IP Periodica Polytechnica

Social and Management

Sciences

23(2), pp. 84-97, 2015

DOI: $10.3311 /$ PPso. 7676

Creative Commons Attribution (i)

RESEARCH ARTICLE

\section{Quality Assessment Criteria and Their Role in the Development of a Successful Educational Project Proposal}

\author{
Daniela Staneva ${ }^{1}$, Matilda Alexandrova ${ }^{2 *}$, George Petkov ${ }^{3}$
}

Received 25 August 2014; accepted after revision 04 December 2014

\begin{abstract}
The paper suggests an analysis of data concerning 306 educational project proposals submitted for European funding in 2013. Several fundamental questions regarding the role of the evaluation for achieving European ideas and goals when financing projects in education area are posed and answers have been provided. The hypothesis that the actual assessment confirms the objectives of the EU is discussed against the alternative that this assessment changes the focus of EU funding. Another natural question that finds an answer in the present work is "How to plan the preparation of the project proposal with a view to optimize its effectiveness and the expected results?" The data is analysed by the methods of histogram analysis, principal component analysis,cross-covariance, correlation and variation analysis, Hilbert's transform, as well as graph's theory techniques.
\end{abstract}

\section{Keywords}

project management, monitoring, evaluation, complex networks

\footnotetext{
${ }^{1}$ Executive Agency of Transplantation, Bulgaria

${ }^{2}$ Department of Management, Faculty of Management and Administration, University of National and World Economy, Bulgaria

${ }^{3}$ College of Engineering, Mathematics and Physical Sciences, Innovation Centre, University of Exeter

* Corresponding author, e-mail: matildaa@unwe.bg
}

\section{Introduction}

The utilization of European funds and the participation in international projects is a trivial topic that always comes on the agenda when we talk about European financing. The present study is based on the analysis of project proposals that are submitted for funding by one of the EU educational programs. This analysis broadens our view not only on the utilization of EU structural funds, but also on our participation in large international projects where educational organizations directly apply for the funding of their ideas.

The present study aims to reconstruct the relationship between the evaluation criteria of the already assessed projects and thus to show the real objectives that are achieved through the funding of European educational programs, objectives that might differ from those written down in the European papers. The aim of this study is sufficiently important by its own because on the one hand, the research methodology can be used in other areas of EU financing, and on the other, it provides a method of feedback and adjustment of the assessment. In reality, by post-monitoring of the evaluation results within a certain period one can receive a feedback and can make appropriate conclusions and corrections to the methods and actions for monitoring and evaluation. The study achieves other purposes as well - for example, another important outcome from the present research is the knowledge of the mechanisms of connectivity between the different quality assessment criteria, which enables us to create an architectural model of a project proposal that may enhance its competitiveness and efficiency.

\section{Literature review}

The current topic has not been studied comprehensively in the literature although the research on project success and failure factors has a long history up to now. The first classification of the success factors was made by Dvir et al. (1998). Most of the scientific articles investigate the project success factors in the area of project management. One of the first model investigations was done by Nabitz (2000). Some of the identified factors for project success are linked to predictability: cost and time, project and operations management methods, etc. 
(Cooke-Davies, 2002). Similar studies have been performed in order to identify specific success factors regarding EU funded projects in CEE (Alexandrova and Ivanova, 2013).

The opposite problem - concerning the factors of project failure - was discussed by Shenhar et al. (2002). Papadaki et al. (2014) investigate factors that contribute positively to the improvement of the effectiveness of project risk management. The study of success/failure factors in project risk management provides further insights into the value-creating processes of projects. In this sense, the approach for project monitoring and control based on earned value management concept suggests a transfer of different technical dimensions of risks into a general cost evaluation framework (Sebestyén and Tóth, 2014).

A number of studies were dedicated to Project Excellence Model (e.g. Westerveld, 2003) dealing with result areas considering project success criteria and organizational areas covering critical success factors, but all of them are oriented towards investigation of the project management factors for success. The importance of project critical success factors across the project life cycle was also investigated which provided answers to various questions related to project management success (Pinto and Prescott, 2012).

There is no doubt that effective management plays a crucial role for project success. However, the circumstances have changed, and nowadays EU employed a preliminary evaluation of the project quality, as well as project management in order to finance or not a particular project proposal. Our motivation behind the present research is that the success of a project proposal cannot be perceived in advance before the final positive decision for its funding. The research is based on the above mentioned sources although it tackles the problems in a different conditional space applying a more deterministic, predictive, and reconstructive approach (Kalitzin et al., 2011). In general, the present article is oriented towards identification of the importance of the project design stages for the project success prior to the submission for EU funding. Moreover, during these stages the general project management framework for monitoring and evaluation should be implemented which provides opportunities for predicting success of the project proposal.

\section{Description of data}

The present study is based on 306 project proposals that have been submitted in the 2013 selection year and have passed an eligibility check. The collected data covers a sufficient diversity of cases to be considered as are liable sample. For each project proposal the following data are known: the results from the ex-ante qualitative evaluation of the project proposal containing assessment in following qualitative criteria - "Relevance", "Quality of the Work Programme", "Innovation", "Quality of the Consortium", "European Added Value", "Costbenefit Ratio", "Impact", "Quality of the Valorisation Plan" and the "Participation of third countries" (where applicable).
All projects that have passed the eligibility check are assessed for their quality. The quality assessment is implemented according to quality criteria listed in Table 1. Taking into consideration the approved five-point scale, every criterion is evaluated from 1 to 5 .

The presented database of 306 project proposals that have passed the administrative capacity assessment is divided into two groups according to the overall consolidated qualitative assessment: good projects (projects with a score of 25 points or higher), i.e. those who are in the second half of the rating scale, and weak projects (projects whose consolidated qualitative assessment is up to 24.5 points), i.e. projects that fall into the first half of the scale. Of course,that division is used for illustration purposes only, as in the present study we are interested in all project proposals, not only of the "good" ones. The point is to reconstruct the relationships between the quality indicators for evaluation, i.e. not only how the higher score on one indicator determines the high score in another, but also how the low score on a corresponding indicator entail slow scores on the related indicators.

Table 1 Description of the quality criteria

\begin{tabular}{ccc}
\hline o. & Criterion (EN) & Abbreviations \\
\hline $\mathbf{1}$ & Relevance & REL \\
\hline $\mathbf{2}$ & Quality of the Work Programme & WPQ \\
\hline $\mathbf{3}$ & Innovative Character & INN \\
\hline $\mathbf{4}$ & Quality of the Consortium & TMQ \\
\hline $\mathbf{5}$ & European Added Value & ADV \\
\hline $\mathbf{6}$ & Cost-benefit Ratio & BVM \\
\hline $\mathbf{7}$ & Impact & IMP \\
\hline $\mathbf{8}$ & Quality of the Valorisation Plan & VAL \\
\hline
\end{tabular}

The data is analysed by the methods of histogram analysis, principle components analysis /PCA/, cross-covariance, correlation and variation analysis, Hilbert's transform, as well as various other techniques and methods from the theory of graphs. These methodological tools have been applied using system functions of the Matlab ${ }^{\circledR}$ package (Mathworks Inc., Natic, MA: USA; release 7.13, 2011b) as well as custom functions developed in $\mathrm{Matlab}^{\circledR}$ environment. On the basis of data analysis relevant conclusions have been made in the studied directions and further guidelines for this research are discussed.

\section{Histogram and space analysis}

Firstly, we present graphically the qualitative assessments of the 306 project proposals on the eight different criteria. Table 1 contains the listed abbreviations of the criteria that are displayed on the following figures.

If we arrange the projects in ascending order according to the total score and derive the distribution of the individual 


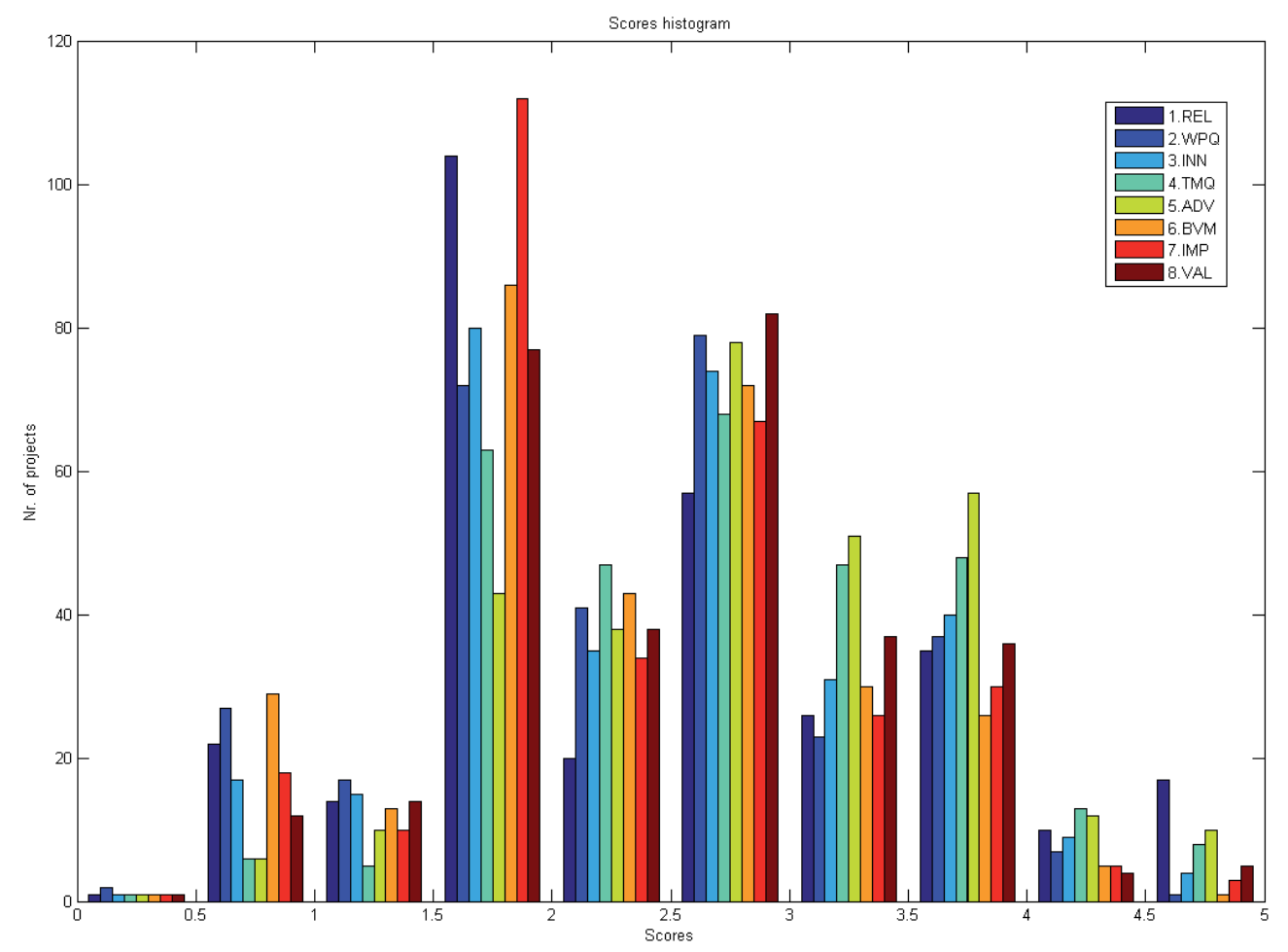

Fig. 1 AHistogram of the assessments

scores by various criteria, we will obtain the histogram shown in Fig. 1. The X-axis shows the different qualitative evaluations which project proposals have received, and the ordinate shows the number of projects that were qualitatively assessed. The individual criteria are colour coded.

The diagram reflects the expected results (Cressie, 1993). The number of projects that have assessments 4.5 and 5 on the different indicators is very low, as well as the number of proposals scoring less than 1.5 on the eight criteria is insignificant. Amongst those proposals evaluated by a low score the largest number are the projects having a score of 2 , which is just below the "quality threshold". A significant number of project proposals have obtained a score of 3 , which is the lowest score sufficient for funding according to certain criteria.

What is striking in the histogram analysis of the assessments (Fig. 1) is that the values for some pairs of different indicators are very similar to each other. This leads to the hypothesis that they might be correlated. Such correlation cannot be concluded out of the histogram similarity alone. In order to search for evidence regarding our hypothesis several data analysis techniques were applied accordingly, including PCA, cross-covariance and cross-correlation analysis with auto-correlation corrections.

Let's suppose there is a certain correlation between the assessments which the proposals have received on indicator 2 (Quality of the Work Program) and on indicator 6 (the Costbenefit Ratio). This can be explained from a management point of view in a way that if a project cannot properly structure its work program, it is natural that its weaknesses in this respect reflect first on the budget and next on the cost-benefit ratio. The second pair of quality indicators- which impresses with its connectedness - is the quality indicator 3 (Innovative Character) and indicator 7 (Impact). The link between the two quality criteria is quite simple-if the project has not offered significant innovation development, it could not justify the degree of impact that would take effect on the target group.

The quality of a project also may depend on the connection that could be hypothesised (similarly to the two previously mentioned pairs of indicators)between the quality indicator 4 (Quality of the Consortium) and the quality indicator 5 (European Added Value). In a previous work (Staneva et al., 2014) we have already investigated the connection that exists between the geographical distribution of the different countries from the consortium and the expected European Added Value. Naturally, a consortium with broad geographical coverage involving countries from different European regional areas will be assessed relatively higher and can clearly show the desired level of European value added. Therefore, a key feature for the success of a project proposal is finding the right balance between the pairs of qualitative criteria by establishing a level of connectivity and their mutual dependence.

Next, we consider all project proposals arranged according to their consolidated overall assessment. The interesting thing in the 3-Dgraph (Fig. 2) is that the groups of projects according to the obtained assessment scores are very clearly separable. If we draw an imaginary line on the critical level of 2.5 points, we can immediately identify the group of projects that participate in the rankings. At the same time,we could find out that the project proposals which do not participate in the rankings (due to low scores on certain criteria) have enviably high scores on the others. This leads us to the hypothesis that the actual reason 


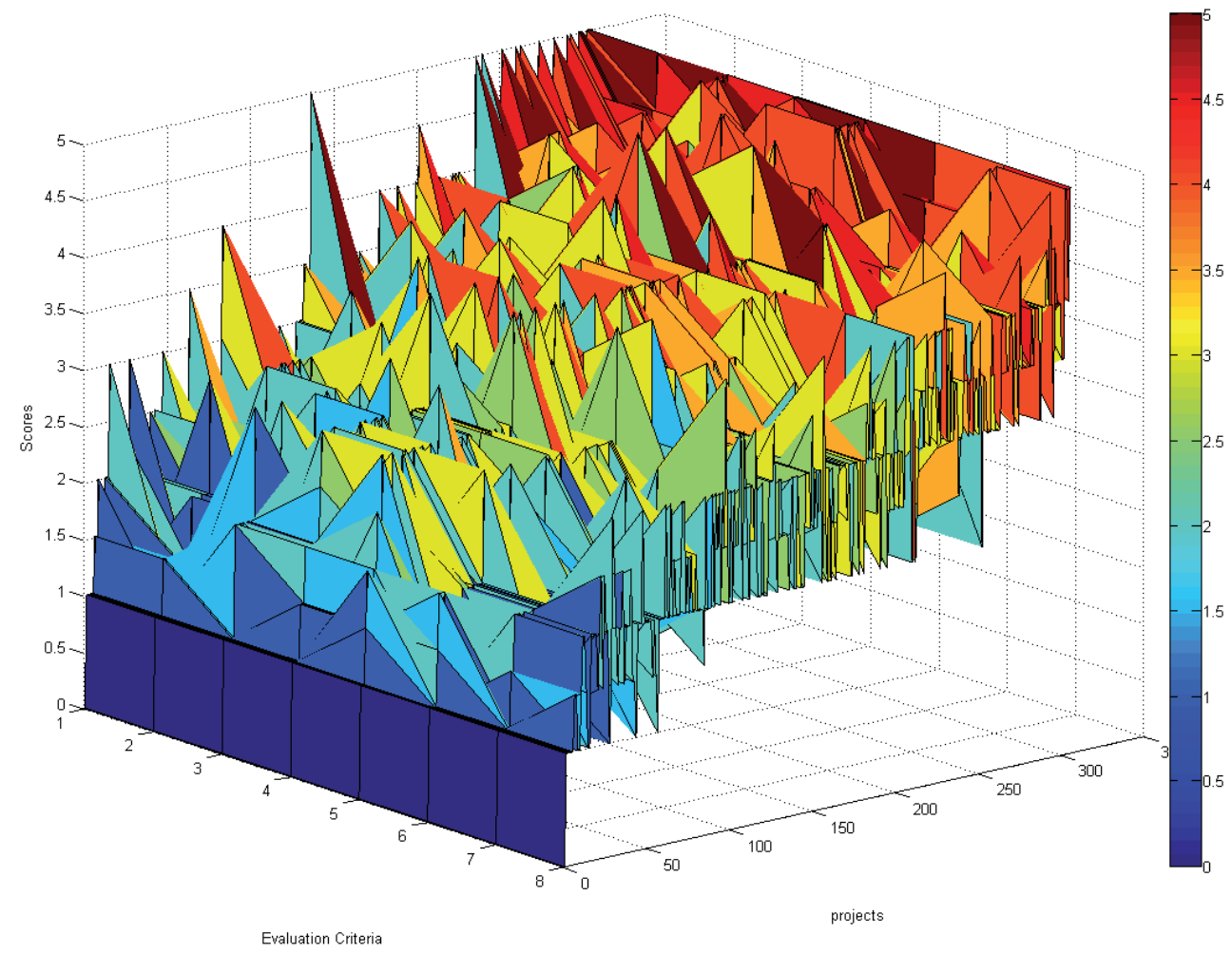

Fig. 2 3-D representation of projects according to the received assessments.

(The project proposals are arranged on the abscissa, the criteria for quality assessment - on the ordinate and the obtained project assessments according to each of the quality criteria - on the applicate and a colour coding of the assessments is provided)

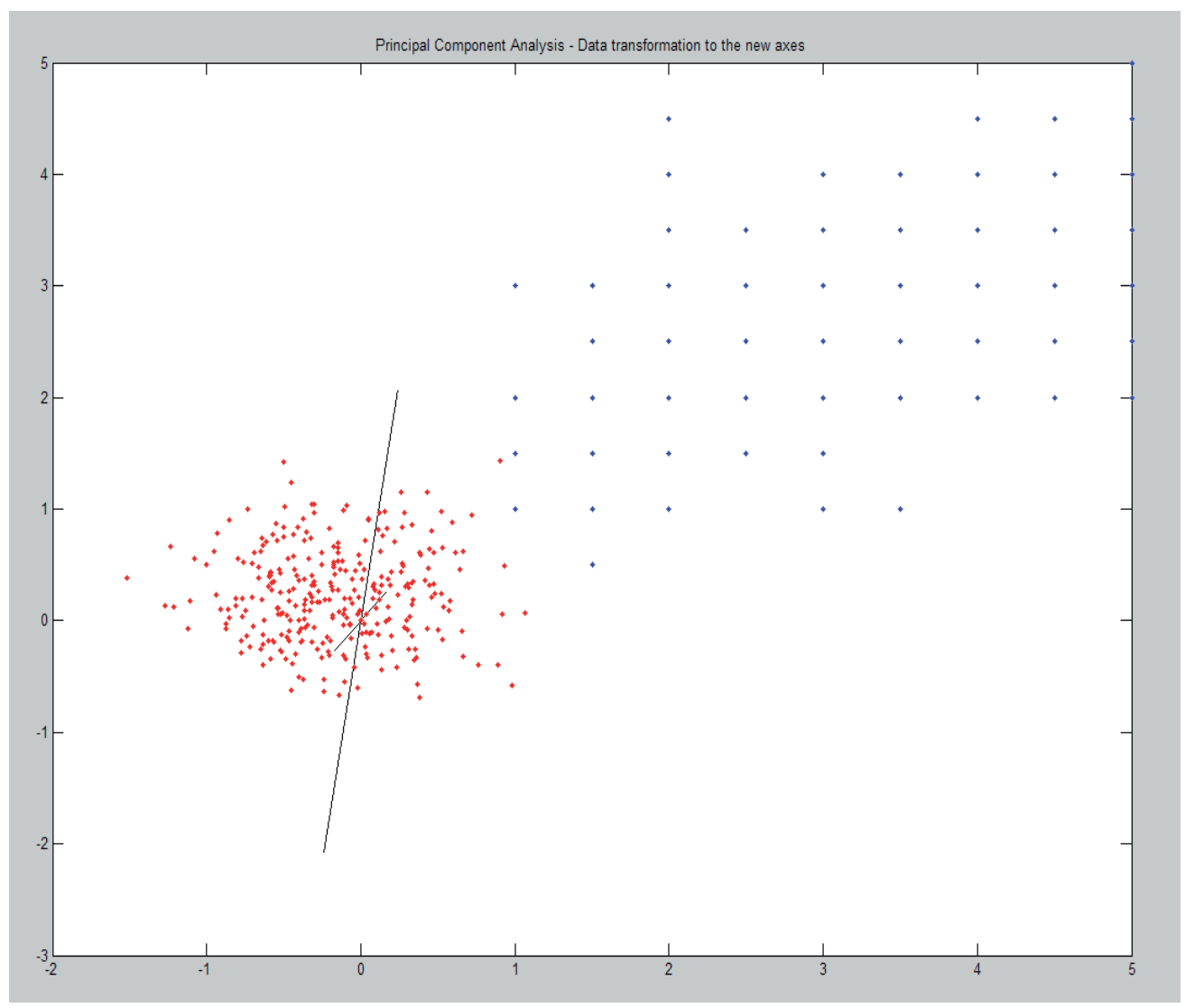

Fig. 3 Application of PCA.

(The bluepoints represent the existing data, the red points represent the data after the application of PCA,and the black lines represent the first two principal components according to which the transformation is made) 

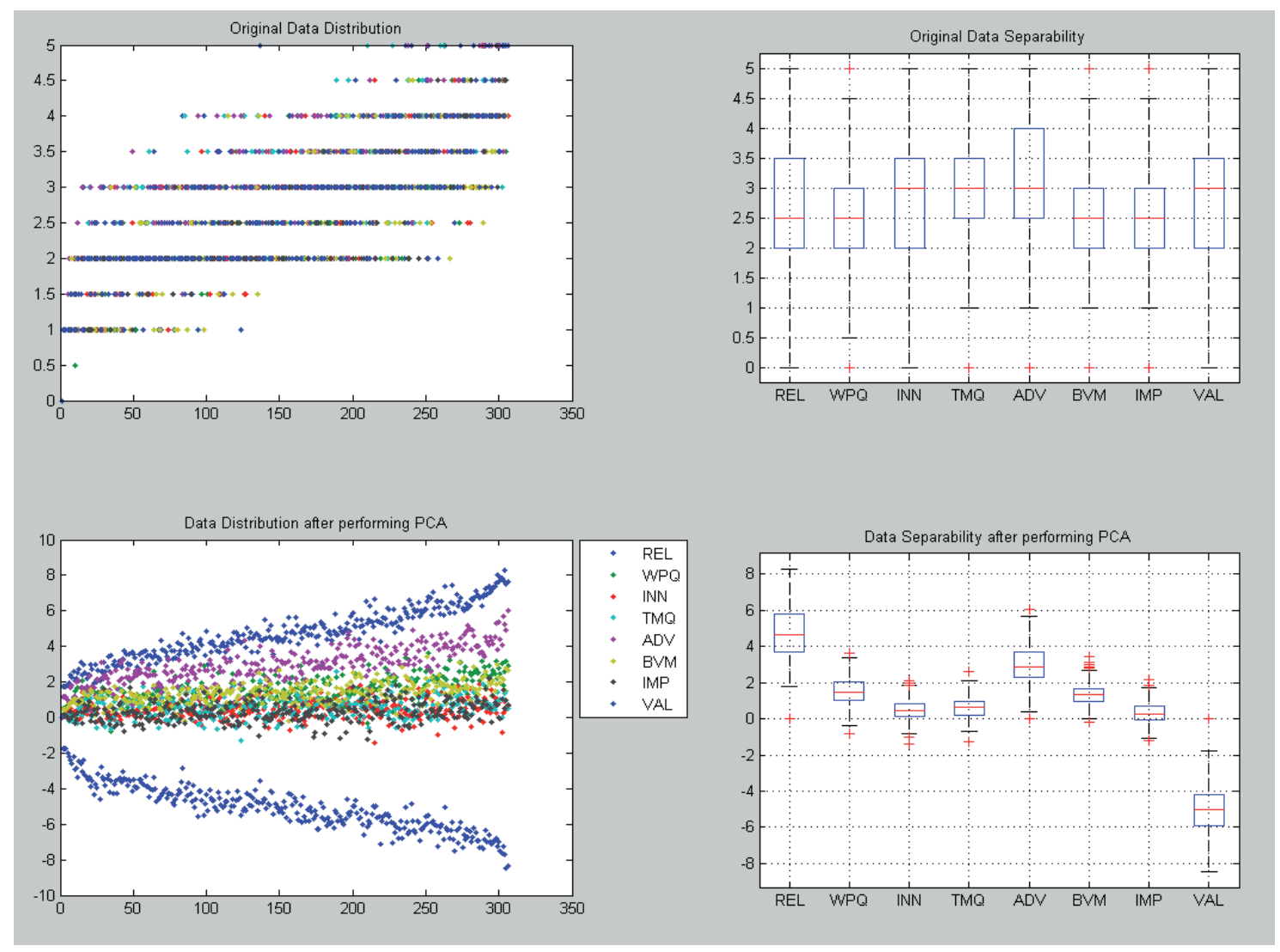

Fig. 4 Separability of the data

for not allowing many projects to get a ranking is the imbalance of these project proposals or the omission of a key element (i.e. factor for success). The third group of project proposals that are obviously weak is clearly visible,since their quality assessment does not exceed a score of 3 in any of the indicators. The good sign about the quality of the submitted project proposals is the relatively lower number of proposals in the third group.

\section{Principal component analysis}

A detailed research based on data analysis about these proposals is hindered by the low separability of quality evaluation criteria. To increase the degree of separability between the different criteria the method of PCA is used. The main idea is that if there is a correlation between the different variable dimensions so that part of the data is redundant. PCA transforms the data in a way that the largest possible variation will be "squeezed" in the least possible dimensions. Thus,we are compressing the data by ignoring some small variations (Brandimarte, 2006). The methodology of the study is implemented through the following consequent steps: the covariance matrix for all the criteria variables is calculated; the eigenvectors and eigenvalues of the covariance matrix are determined; the data is transformed using the first two eigenvectors (Fig. 3) since the magnitudes of the rest eigenvalues are very close to zero, or even negative (i.e. the corresponding eigenvectors are not presenting significant data dimensions).

This way the first objective is achieved, i.e. the data is now low-dimensional and on Fig. 4 the achievement of the second main objective is illustrated as well, namely the increasing of these parability of the data. The figure consists of four plots. On the top right the distribution of the original data is shown and at the bottom left the data about the covariance matrix is presented where the horizontal axis represents the projects, and vertical axes - the received assessment scores. Each vertical line (project proposal) contains eight different colour points corresponding to the assessment scores obtained by each of the quality criteria. Compliance with color-coding is given in the legend and is common for both graphs. The two left graphs of the figure (above and below) present the results of the statistical analysis of separability between the different criteria in the original data as well as in the data after applying the PCA. In the two "box-plots" (top and bottom right) the abscissa represents the criteria and the ordinate respectively the values of the received assessment scores. The blue rectangles represent the statistical distribution of the criteria's values. In each rectangle the central red marker is the average assessed score, the edges of the rectangle are the 25th and 75th percentiles, whiskers are extended to the most extreme points without substantial differences in the values, and any larger differences are mapped separately by red pluses.

In the two "box-plots" on right column (top and bottom, Fig. 4) the differences between the evaluation criteria are shown without making any assumptions about their basic statistical distribution, i.e. they are non-parametric,indicate the degree of dispersion and skewness in the data (Brandimarte, 2006), and identify the extreme values.

The presented statistical analysis on Fig. 4 (lower right plot) clearly shows five groups of factors (separated horizontally) 
that need to be addressed separately and thoroughly while preparing a project proposal. More than one factor in some of the groups means that the corresponding themes need to be simultaneously addressed in their close interrelations and mutual dependencies. Our hypothesis is that project proposal developers could use the average value for each factor (evaluation criteria shown on Fig. 4) as a quantitative indicator for measuring the degree of its importance. The greater average value for a specific criterion means higher weight of the theme associated with it. In this case, the order of the factors changes as follows:

1. "Relevance";

2. "European added value";

3. "Quality of the work program" and "Cost-benefit analysis";

4. "Innovative character", "Quality of the consortium" and "Impact";

5. "Quality of the valorization plan".

The present findings cannot be considered completely accurate as they are based on the importance of the criteria in the evaluation system, but not on the relationship between the criteria, yet to be considered. The relationships between the evaluation criteria can assist the tests of formulated hypotheses. An analytical hypothesis requires top-down order of examination, i.e. first to clarify the issues about the most important criteria for the final assessment, while a synthetic hypothesis requires a reverse order, i.e. through the gradual clarification of the issues related to criteria with less weighting.

\section{Cross-covariance and cross-correlation analysis}

In order to continue data analysis we need a projection in the two-dimensional space. In order to maintain the three-dimensional data we retained the projects and the evaluation criteria (axes in Fig. 5) and the assessment score value is expressed as colour code, i.e.by changing the intensity and colour of the plot.

In the upper plot of Fig. 5 all projects are presented on the horizontal axis arranged according to the increasing value of their total assessment score and on the vertical axes the evaluation criteria are presented. The assessment scores are presented by different colours and intensity starting from dark blue (the lowest score) through green, yellow, orange, red and dark brown (the highest score). The bottom left and right plots of Fig. 5 are constructed by the manner just described where the left plot shows the "weak" projects (with overall score under 25 points) and the right plot represents the "good" projects (with scores from 25 to 40 points).

Now we will examine the relationship between the criteria and will compare them in pairs. Each particular criterion was compared to the rest (Fig. 6) in order to understand whether any of the rest 7 criteria may predetermine or at least have a some influence on the formation of the one in focus. Each of the twenty-eight plots on Fig. 6 visually presents the one-byone comparison of the examined 8 criteria.

The horizontal axis of each of the plots in Fig. 6 represents the projects and the vertical axes - the two criteria in question. Assessment score values are colour-coded.Obviously,the visual inspection of the exhibit cannot give a strict result so it is used rather from an intuitive point of view. To be able to compare the 2 criteria in terms of their mutual commitment we should use the analysis of their cross-correlation matrices. The choice of cross-covariance and cross-correlation analysis (e.g. Kraay and Driscoll, 1998) is not accidental,since these methods compare the similarity of two functions and, according to their results,we could assess not only whether any two variables are considered interdependent but the direction of their relationship.
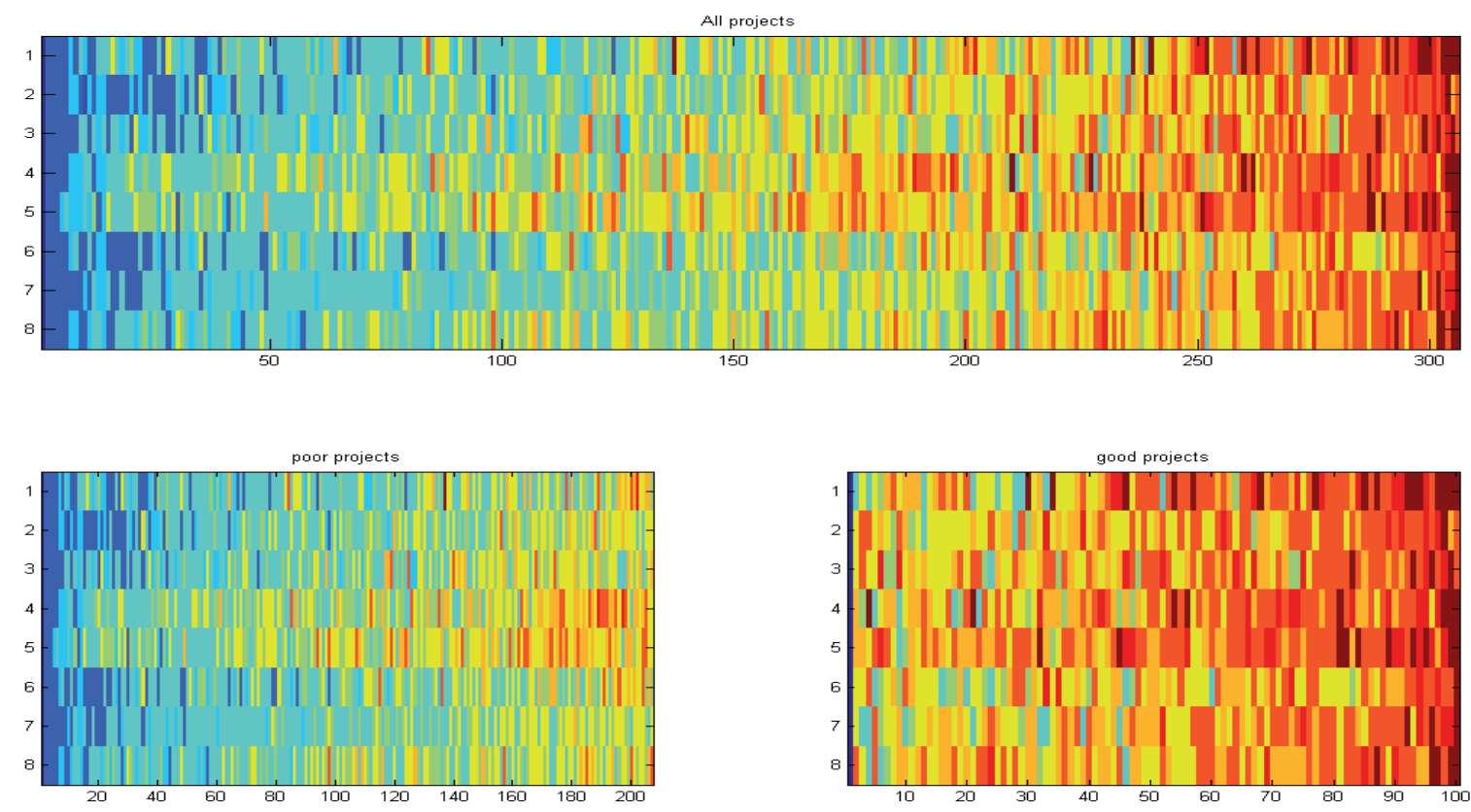

Fig. 5 Two-dimensional presentation of the distribution of the projects according to indicators and assessments. 


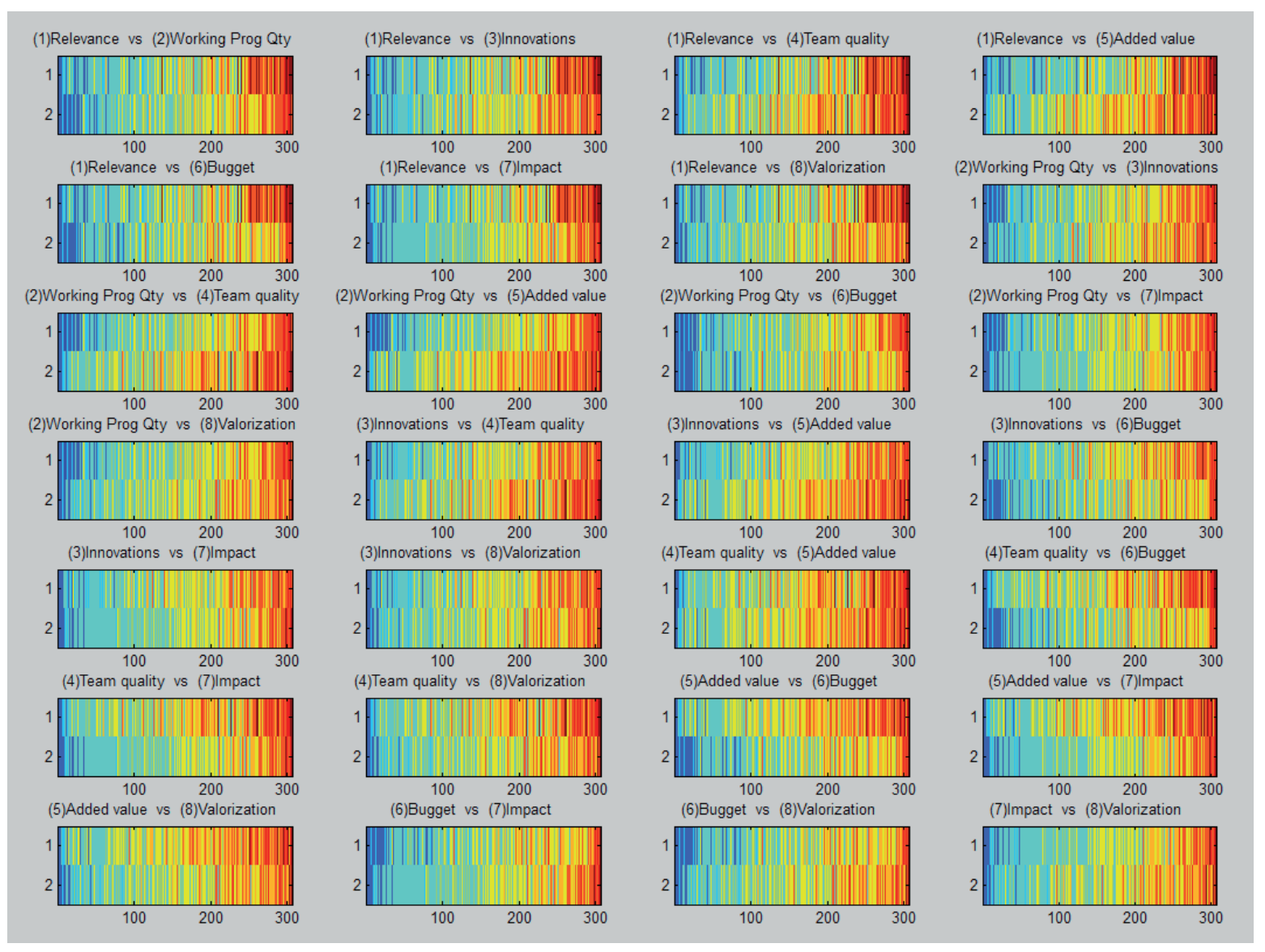

Fig. 6 Two-dimensional presentation of the distribution of the projects couples' indicators (all pairs).

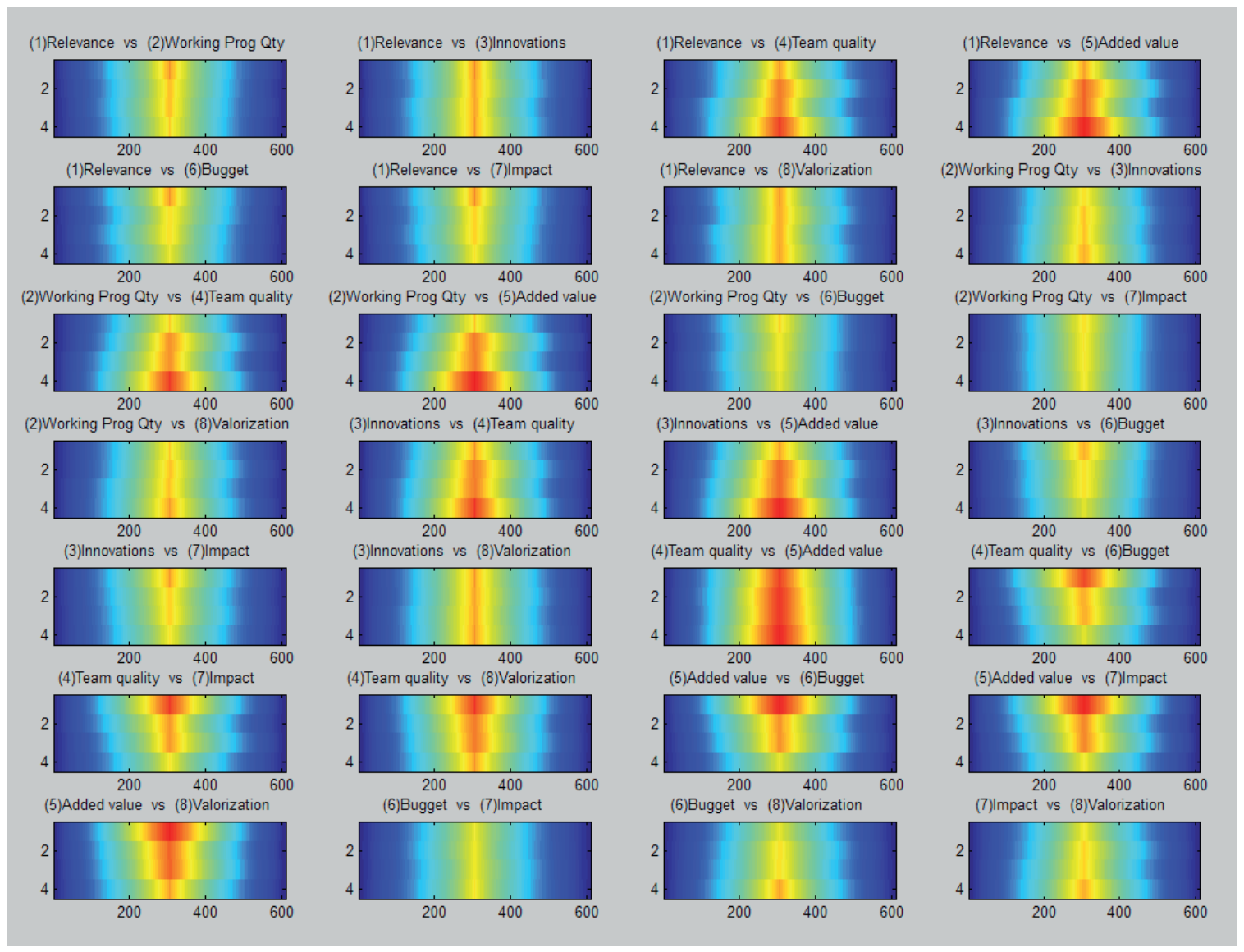

Fig. 7 Cross-correlations in pairs of criteria for comparison - Relevance, Quality of the work program, Innovative character, Quality of the consortium European added value, Cost-benefit impact, Quality of the valorisation plan 


\section{Investigation of connections between the different criteria}

The study of the relationships which exist between the different quality criteria helps us to understand the logic of the process of evaluating the project proposal and to demonstrate the relationship between the different qualitative criteria in order to build a system for ex-ante project proposals' evaluation. The methodology of this study is based on a comparison of pairs of criteria by cross-correlation taking into account the influence of autocorrelation.

On Fig. 7 the values of the auto-correlation function for each pair of the evaluation criteria are presented. The horizontal axes of each plot on Fig. 7 represent the projects, multiplied by two; the values on the left half correspond to a directional connection from the second to the first criterion, and the right half - vice versa. The vertical axes of each plot on Fig. 7 has four rows, where: the first row corresponds to the cross-correlation between the first and the second criteria; the second row corresponds to the auto-correlation of the first criterion; the third row corresponds to the auto-correlation of the second criterion, and the fourth row corresponds to the cross-correlation between the second and the first criteria. The cross-correlation analysis reveals the relationship between qualitative criteria. Reading the data the following cross-correlations are computationally differentiated:

- The influence of the Relevance on the Quality of the Work Program and on the Impact is clear and unambiguously determined;

- The relationship between the following two pairs of quality criteria: "Relevance" - "Innovation" and "Relevance" - "Valorisation" (exploitation and dissemination of results) is equalized. The reason for this mutual influence results from the fact that the projects are oriented towards elaborating something new, towards developing innovative elements that should be implemented and disseminated in all partner countries.

- "Quality of the consortium" and "European added value" in turn influence the "Relevance" as a quality criterion, because the consortium capability is decisive whether a given project idea will be successfully implemented or not,as well as the presence of European added value justifies the project's relevance.

The study of the interconnection and the dependencies between the different criteria is carried out by the means of both instruments mentioned above, and is discussed in detail according to the different criterion.

"Relevance" is the main criterion for the quality of the project proposal. It is connected with the project objectives and project outcomes which should be achieved and consistent with the priorities of the program to which the project has been referred. This criterion naturally influences on all others (Fig. 7), and on the overall assessment of the project. The Relevance of the project proposal evaluates the significance of the proposed project compared to the present status of situation.

Criterion "Relevance" the most influences the Quality of the Work Program. Through this criterion evaluates whether the planned final project results/products comply with the policy of the program.

Each activity in the project implementation is subject to the "Relevance" criterion: the project innovativeness should not be a goal in itself, but should be subjected to the project idea; the Consortium gathers and unites for the implementation of this idea. Finally the relevance affects the Cost-benefit,ratio otherwise the spending it would not be justified in the terms of European financing. The Relevance is related to the Impact that is expected to exert on the target group, and to what extent it will meet the needs of individual project users. The criterion influences also the Valorisation plan that will enable the dissemination and exploitation of project results.

Through a research of the values in the cross-correlation matrix we proved the leading role of the "Relevance" in respect to five of the eight criteria. The Relevance determines the quality of the project idea through which the policy of the program is implemented. The realization of the project idea related to the suitability of the project directly affects the expected impact of project results. This supports the conclusion about the leading role of the relevance assessment regarding the general trend of the project evaluation.

Criterion "Quality of the work programme" evaluates how to achieve the objectives of the project proposal. This criterion is crucial for the overall performance of the project. It indicates at which extent the programme's objectives could be achieved and whether the target groups' needs could be met. Work program includes elements related to the organization of activities and hence influences the spending of budget resources. Its influence on the "Project impact"that is achieved through the realization of the project results is very clear. The actual quality of the work program depends on the ability of the partner organizations' "Consortium"to implement the plan. The "European added value"as a projects' goal will also influence the project work program - however, the funding of educational projects is not a goal of itself - it should be subject to the programme policy.

The relation "Quality of the work programme" -"Innovation" is clearly defined since the essence of the European program is aimed at developing innovations. Therefore, the innovation of the project proposals is initially determined."Innovative Character" criterion determines the evaluation of the of the rest qualitative criteria.

According to the values of the connections shown on Fig. 7 the innovative nature of the project most strongly influences the Impact that the project may have. The significant innovative elements affect the Cost-benefit ratio. Any major innovation is justified in terms of budgetary resources provided the 
Impact is significant. The most important is the relationship between project Innovation and the Impact of the project - the more innovative the project is, the greater the impact of its results on the target group will be. From another perspective the innovative elements in a project depends on the quality and the composition of the consortium that will implement the project because only quality team can participate in implementation of significant and innovative ideas.

The Innovation is directly connected with the European added value because the outputs and the change in the European policy, theory and practice in education can happen through innovative ideas. A bilateral is the relationship between the innovative project elements and the valorisation of the project - the significant innovation projects more easily disseminate their results and easier the innovations reach the project target group. On the other hand, the use and dissemination of the project results and products is significant only when the project is innovative.

"Quality of the Consortium" - as a quality criterion affects the very implementation of the project. The consortium is assessed in terms of its ability to achieve the intended results and from there the assessment is focused on possibility the various organizations in the consortium to participate actively in the dissemination of results and to cause significant impact on the project target group. An important point in assessing the quality of the consortium is the balanced participation of the project partners (Fig. 7). Consortium quality is not a leading criterion; however, it appears to be a result of the evaluation of the European value added because only a highly competent team is able to achieve significant results.

Criterion „European Added Value" - each project funded by a European program should add value. This criterion strongly influences the Impact of project results - only project with significant added value can achieve significant impact, can influence the quality of the program for dissemination of the results, and can be justifiable from the perspective of costbenefits ratio (Fig. 7).

Criterion „The Cost-benefit Ratio" - the project budget is a result of the planned work program through which a project can be realized (Fig. 7). All seven quality criteria affect the project budget. The assessment of the cost-benefit of the project is best measured by the impact that the project results have on the project target group. The qualitative evaluation of the costbenefit ratio is crucial for the project proposal selection. All costs must be justified where adequate resources are planned (e.g. personnel, equipment, travel,materials, etc.) necessary for the effective and efficient project execution.

Criterion "Project Impact"- it aims to support the achievement of a significant effect in respect of the project idea. During the impact assessment the effectiveness of the resource plan is assessed (Fig. 7). The impact assessment allows evaluators to compare the input resources to the expected output results and to assess at what extent the various resources can be efficiently used. The Impact is influenced by the dimension of the utilization and dissemination of results.

Criterion "Quality of the Valorisation Plan"- the lattercriterion should have a positive impact on the sustainability of project results, therefore this criterion influences the project impact on the surrounding environment.

\section{Valuing the connectivity}

The relations examined above together with the degree of interaction between the criteria are analytically confirmed by the examination of the extreme values of the corresponding cross-correlation matrices (Fig. 8) demonstrating again the interdependence of the criteria from each other. The cross-correlation values are normalized using the sample data. The normalized cross-correlation shows the relationship between any two tested criteria (Kraay and Driscoll,1998) on the basis of 40 selected most similar projects with a $95 \%$ statistical level of confidence, checked with the Pearson's criterion. The value of two standard deviations was used as a threshold which provis at least $95 \%$ level of confidence.

The values are normalized in the range between zero and one and are directly comparable. The high cross-correlation levels indicate that the selection of the criteria is made in order to achieve the EU programme's goals.

The main objective of this study is to build a matrix of connectivity (adjacency matrix) between the quality criteria (Thiessen, 2013), i.e. to construct a graph of the criteria. A "graph" in this context is made up of two sets:"vertices" or "nodes", and lines called edges that connect them. The adjacency matrix, sometimes also called the connection matrix, of a simple labelled graph is a matrix of non-negative numbers with rows and columns labelled by graph vertices. The number in position (edge)represents the strength of the connection between the nodes and if and only if the nodes and are not adjacent. Only symmetric adjacency matrices were considered, which does not limit the research consistency because the directionality may be derived from the time lags of the applied cross-covariance function. The problem of reconstruction of criteria's connectivity (functional connectivity) will be approached by means of multi-scale analysis. We used two methods for inferring the network structure from the data. The method's choice reflects the connectivity properties in different scale spaces.

The first approach is based on the valuation of the crosscorrelation calculated for the observed criteria. Based on the normalized cross-correlation in the zero position, we built the adjacency matrix of connections and we have examined different thresholds to identify the importance of each connection (Cressie, 1993). The second approach is based on a more complex but more direct technique. The measure, based on the second approach for determining the functional connectivity, is the phase-locking factor (PLF) which is derived directly from the analytical signal (the initial data processed with 


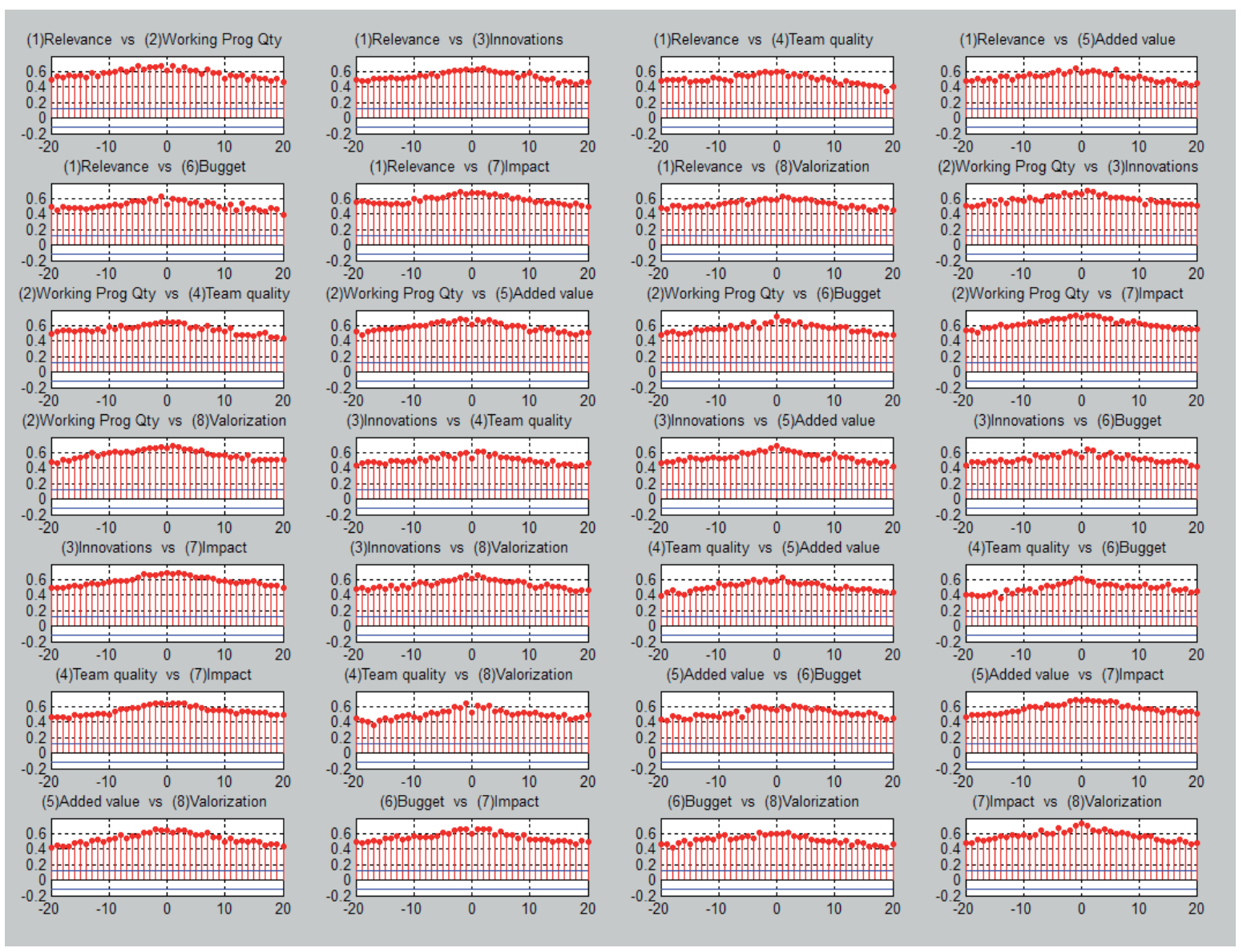

Fig. 8 Normalized cross-correlation pairs criteria based on partial sample. The blue lines indicate the threshold level.
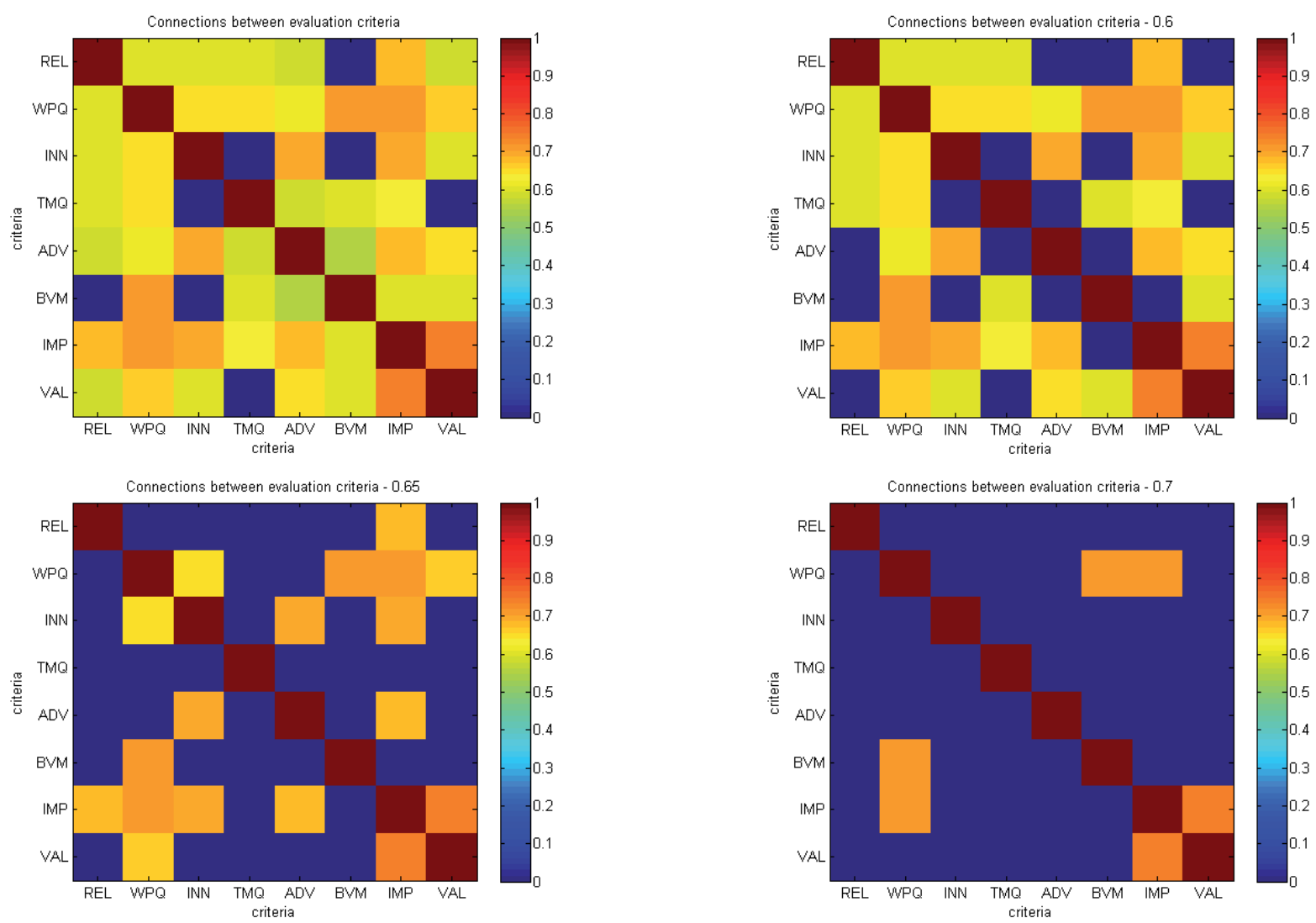

Fig. 9 Values of the normalized cross-correlation with threshold of $95 \%$ level of confidence. 
integral Hilbert's transform) taking the mean of the instantaneous phase difference between each pair of criteria. Here we note several important reasons to use two completely different approaches operating on different scales. Suppose that if by each of the two described approaches we come to radically different results, then the conclusion would be that the relationships between the criteria defy the analysis. The use of two radically different approaches when constructing the adjacency matrix and the achievement of similar results in each of them ensure, on one hand, the correctness of there search and the accuracy of the calculations, and on the other hand, shows the sustainability of the result (i.e. the connectivity pattern).

The adjacency matrix (Fig. 9) was obtained by using of thenormalised cross-correlation at non-zero time lags. The $\mathrm{X}$ and
$\mathrm{Y}$ axes represent the evaluation criteria and the colour indicates the strength of the interrelation. Again,the values are shown in colour-scaled normalized data between 0 and 1. Fig. 9 contains four plots where a threshold of two standard deviations is used (value of 0.1). The first plot shows the values of the connectivity (adjacency) matrix with a threshold of 0.55 , i.e. more than ten standard deviations; the second plot has a threshold of 0.6. The third and fourth plots are made with thresholds 0.65 and 0.7 respectively. Analysing the results we can track the strength of interaction between the criteria; starting in reverse order one may trace the generic and the connectivity strength between the qualitative criteria.

On Fig. 10 the adjacency matrix obtained after the application of phase locking factor is depicted. The figure contains five
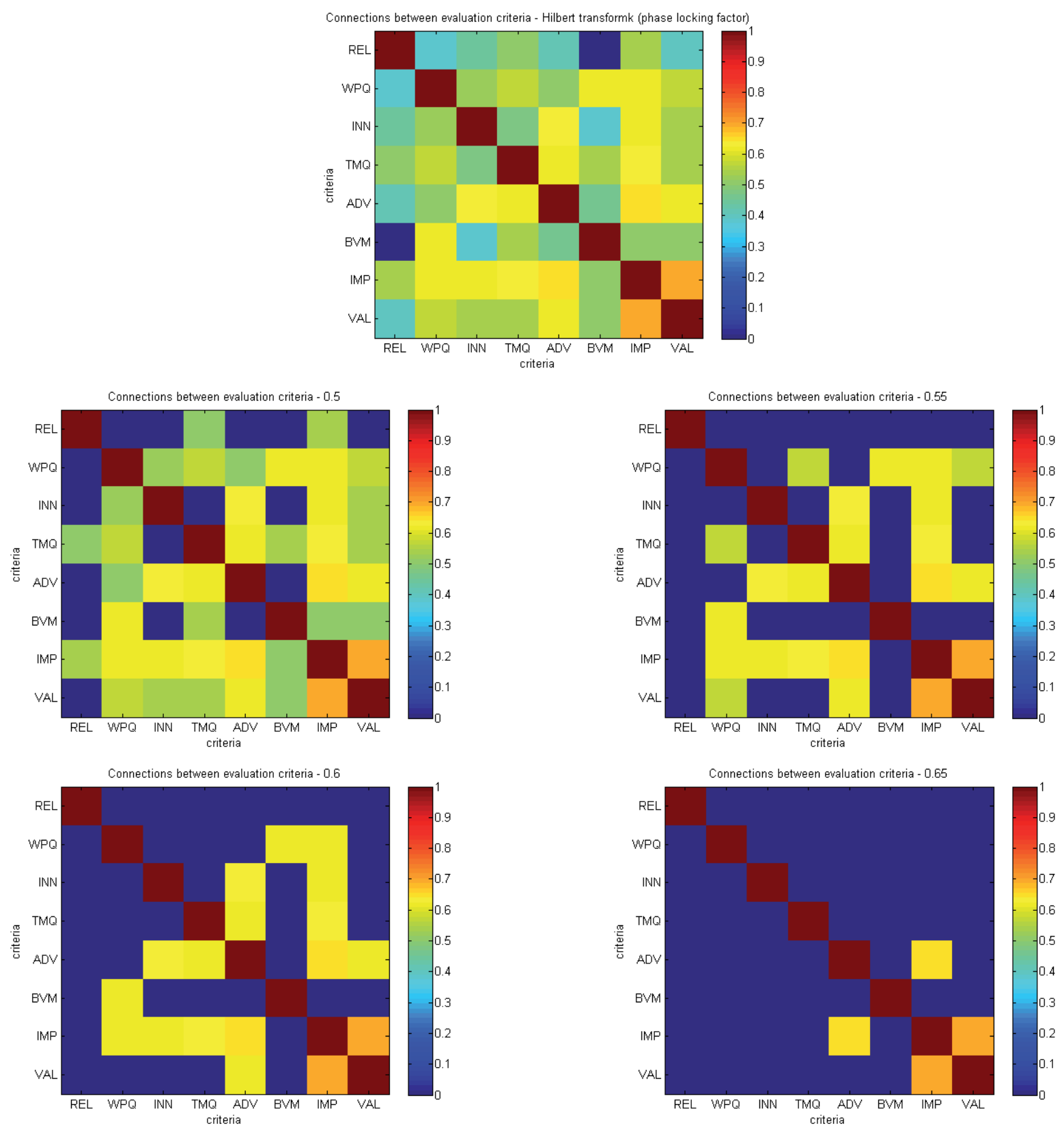

Fig. 10 The values of the associative matrix obtained as a result of the Hilbert transformation. Visually observed fluctuations of the data are typical for the results obtained by a multi-scale analysis. Based on the computational results we investigate the following hypothesis: "There exists a constant which, multiplied by the adjacency matrix obtained by the Hilbert integral transformand added to the adjacency matrix for med by the cross-correlation function, will return zero". The result is shown on Fig. 11 (third plot)by applying 0.9 as the valueof the searched constant. 


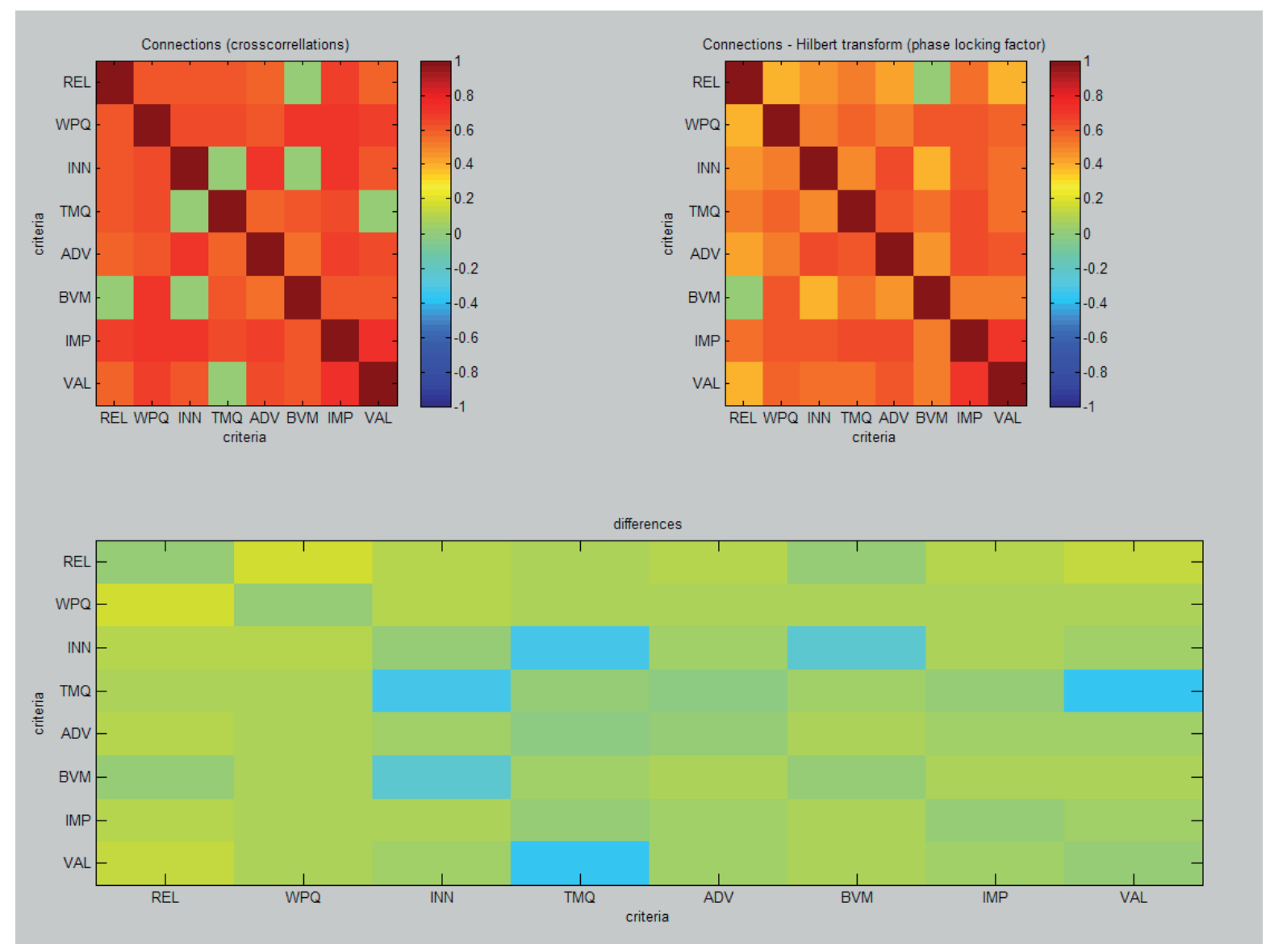

Fig. 11 Comparison of the results of achieving the adjacency matrix.

plots with data normalized between 0 and 1 where the threshold of 2 standard deviations has 0.1 value. The first plot shows the values of adjacency matrix with threshold of 0.45 , i.e. more than 8 standard deviations, the second plot has a threshold of 0.5 and the third - a threshold of 0.55 . The fourth and fifth plots are created by thresholds respectively 0.6 and 0.65 .

The main result presented on Fig. 11 follows from the comparison between the first plot in Fig. 9 and the first plot in Fig. 10 (which are plotted again as first and second plot on Fig. 11). Besides the visual comparison, a numerical comparison of the adjacency matrices is performed as well and presented as the third plot on Fig. 11. It may be noticed that the differences between the results obtained by the two approaches are minimal. In order to evaluate the difference in both positive and negative directions we have presented the adjacency matrices in a different colour scale containing positive and negative values. The differences at the selected constant are within the magnitude of $10 \%$ in positive and negative direction.

The optimal value of the constant for which the differences are minimal can be found as well. The solution of the corresponding optimization problem lays beyond the present study, because we have already shown the two basic properties of the resultant adjacency matrix:

- first, the possibility of instability of the findings is less than $10 \%$, i.e. with $90 \%$ probability we can claim that we have correctly reconstructed the adjacency matrix;
- second, the differences do not affect the connectivity, i.e. independently from which matrix we use for the reconstruction of the connections, we reach the same graph.

To be able to formulate the right conclusions from the studies we should interpret the received results in a qualitative and functional way.

Figure 12 presents the results of this research as edges in a directed graph whose nodes are the quality criteria for the evaluation of a project proposal. Each node of the graph is tinted in a different colour, matching with the colour of the edges coming out of this node. The bidirectional edges are black-coloured and form a cycle in the graph. The graph on Fig. 12 is not a simple directed graph but a special case of graph called"network" (Keller, 2007). The network type graphs are characterized with two special nodes: one from which the edges only come out (called BEGINNING nodes) and another in which the edges only get in (called END nodes). In our case the BEGINNING is the "European added value"and the END is the "Budget". This structure reflects most closely the logic of the European projects. They aim to achieve European value added for a relevant (acceptable, fundable) price. In the network type graphs one may define and examine the levels of nodes 'importance as well as the concepts about shortest path between each pair of nodes.

In the terms of graph theory we may give a recommendation about developing a successful project. As a quantitative 


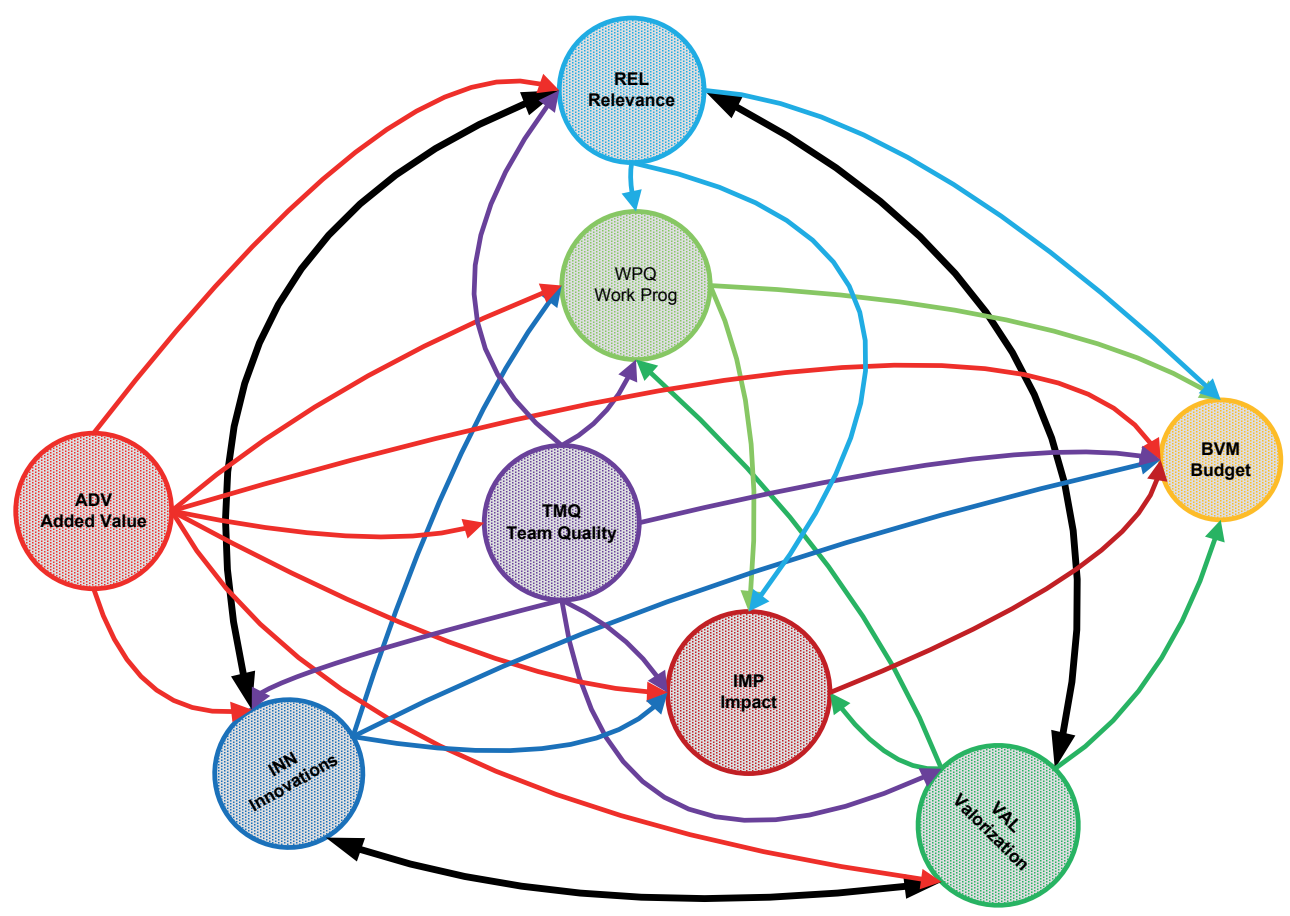

Fig. 12 A graph of the connectivity between qualitative criteria.

indicator for measuring the importance order of the different themes/factors/, the dynamic arrangement of the factors from Fig. 4 is modified as follows:

1 "Relevance";

2 "European added value";

3 "Quality of the work program " and " cost-benefit";

4 "Innovative character", "Quality of the consortium" and "Impact";

5 "Quality of the valorization plan".

Taking into consideration the relationship between the evaluation criteria (Fig. 12) we could confirm or reject any formulated hypothesis. According to the terms of the graph theory the criteria are listed as follows:

- The most important step is to reach a certain European added value! This is the node from which all the connections are starting (the beginning node), i.e. this is the place where a project proposal developer has to start.

- During the second phase the Consortium should be constituted in a way to be convincing in its capability to implement the required European value added. Only one arrow comes from the beginning node to the Consortium node.

- At the next logical level the nodes involved in the cycle Relevance-Innovation-Valorization should be considered simultaneously,as they are dependent on each other (i.e. they cannot be considered and implemented consecutively). These nodes get lines only from previously considered nodes "European added value" and "Consortium".

- During the next step the Work program should be developed, followed by the formulation of the Impact.
- At the end, all activities planned in the project proposal should be financially assured by the respective components in the Budget.

\section{Conclusions}

As shown in the latter section, the analysis carried out by the means of graph theory does not contradict to the tested hypothesis but rather clarifies additionally the applicability of the model. We conclude that the development of a successful educational project proposal could follow the sequence:

- Clarification of the project concept in order to add value with European dimension (European Value Added), in other words, only projects that are significant at the European level have the chances to be funded by the centralized European programs.

- Involvement of partners and establishment of a Consortium that is capable to fully contribute to the realization of the project idea (Quality of the Consortium).

- At the next stage, but not less important - establishment of interaction between three project components: (1) project's compliance with the objectives and the priorities of the funding program (Relevance); (2) clear focus on innovative approaches and solutions (Innovative character); (3) promotion and implementation of the anticipated innovations (Quality of the valorization plan).

- The Quality of the work program is a component which is a function of the aforementioned five components- it is the means by which the suggested innovative solution could be realized. Therefore, the Quality of the work program is influenced by the predecessor components and 
can only have an impact on the Cost-benefit ratio and on the Impact of the project.

- The Project Impact is a result of the successful implementation of the planned activities, so as a component of the project proposal, it only affects the financial resources necessary for its effective achievement.

- Cost-benefit analysis is the last component of the development of a "good" project proposal. All project activities are reflected in the budget plan (from the European added value to the impact that the project could have by its realization), this is why a rational budget is also a key to the successful project proposal.

A future task is to explore the parameters of successful multilateral European projects. The aim is to formulate basic rules that should be followed when initiating a project idea and establishing a consortium in order to be maximum convincing in the project proposal's success. On this basis, we will aim in developing a feasible strategy for an ex-ante evaluation of project proposals ensuring highest chances for them to perform in the segment of the best projects during their execution. The conclusions may have significant contributions to the design of a model for managing the process of developing educational project proposals based on the monitoring and evaluation tools of European educational programs. The model should clarify the relationships between the project proposal's components and allow the improvement of the management system for preliminary monitoring and evaluation of project proposals which apply for funding through the centralized European educational programs.

\section{References}

Alexandrova, M., Ivanova, I. (2013) Critical Success Factors of Project Management: Empirical Evidence from Projects Supported by EU Programmes. In: Kikerkova, I. (ed). Systemic Economic Crisis: Current Issues and Perspectives. Skopje: University of Skopje.

Brandimarte, P. (2006) Numerical Methods in Finance and Economics: A MATLAB-Based Introduction. New Jersey: Wiley-Interscience. DOI: $10.1002 / 0470080493$

Cooke-Davies, T. (2002) The "Real" Success Factors on Projects. International Journal of Project Management. 20 (3). pp. 185-190. DOI: 10.1016/S0263-7863(01)00067-9

Cressie, N. (1993) Statistical Analysis for Spatial Data. New York: John Wiley.
Dvir, D., Lipovetsky, S., Shenhar, A., Tishler, A. (1998) In Search of Project Classification: A Non-Universal Approach to Project Success Factors. Research Policy. 27 (9). pp. 915-935. DOI: 10.1016/S0048-7333(98)00085-7

Kalitzin, S., Petkov, G., Koppert, M., da Silva, F. L., (2011) Reconstructive Modelling: Can We "Reverse Engineer" the Connectivity of the Brain?. World Congress on Engineering and Technology. Shanghai.

Keller, A. A. (2007) Graph Theory and Economic Models: from Small to Large Size Applications. Electronic Notes in Discrete Mathematics. 28 (1). pp. 469-476. DOI: 10.1016/j.endm.2007.01.065

Kraay, A. C., Driscoll, J. C. (1998) Consistent Covariance Matrix Estimation with Spatially Dependent Panel Data. Review of Economics and Statistics. 80 (4). pp. 549-560. DOI: 10.1162/003465398557825

Nabitz, U., Klazinga, N., Walburg, J. (2000) The EFQM excellence model: European and Dutch experiences with the EFQM approach in health care. International Journal for Quality in Health Care. 12 (3). pp. 191 202. DOI: 10.1093/intqhe/12.3.191

Papadaki, M., Gale, A. W., Rimmer, J. R., Kirkham, R. J., Taylor, A., Brown, M. (2014) Essential Factors that Increase the Effectiveness of Project/ Programme Risk Management. Procedia - Social and Behavioral Sciences. 119 (19). p. 921-930. DOI: 10.1016/j.sbspro.2014.03.103

Pinto, J. K., Prescott, J. E. (1988) Variations in Critical Success Factors Over the Stages in the Project Life Cycle. Journal of Management. 14 (1). pp. 5-18. DOI: 10.1177/014920638801400102

Santarelli, E. (1995) Directed Graph Theory and the Economic Analysis of Innovation. Metroeconomica. 46 (2). pp. 111-126. DOI: 10.1111/j.1467-999X.1995.tb00373.x

Sebestyén, Z., Tóth, T. (2014) A Revised Interpretation of Risk in Project Management. Periodica Polytechnica Social and Management Sciences. 22 (2). pp. 119-128. DOI: 10.3311/PPso.7740

Shenhar, A. J., Tishler, A., Dvir, D., Lipovetsky, S., Lechler, T. (2002) Refining the Search for Project Success Factors: A Multivariate Typological Approach. $R \& D$ Management. 32 (2). pp. 111-126. DOI: $10.1111 / 1467-9310.00244$

Staneva, D., Alexandrova, M., Petkov, G. (2014) Local and Global Measures for Success and Reconstructive Determination of the Optimal Number of Partners in European Educational Projects. Economic Alternatives.

Thiessen, H. (2013) Measuring the Real World: A Textbook of Applied Statistical Methods. West Sussex: John Wiley.

Westerweld, E. (2003) The Project Excellence Model®: Linking success criteria and critical success factors. International Journal of Project Management. 21 (6). pp. 411-418. DOI: 10.1016/S0263-7863(02)00112-6 